\title{
Physical Activity and Perceived Barriers among Type2 Diabetic Patients in Erbil City
}

Rezhna Abdullah Ahmed; Department of Nursing, College of Nursing, Hawler Medical University, Erbil, Iraq. (Correspondence: rejna92@gmail.com)

Ronak Nihmatala Hussain; Department of Nursing, College of Nursing, Hawler Medical University, Erbil, Iraq. Iraq.

\begin{abstract}
Background and objectives: Physical activity is necessary for providing a healthy lifestyle, improving quality of life, controlling diabetes mellitus and promoting glycemic control. The aim of the study was to assess physical activity and to determine barriers to physical activity among type 2 diabetic patients in Erbil city.

Methods: A cross-sectional study was conducted among 400 type 2 diabetic patients, attending Layla Qasim Center in Erbil City during May 27 to 30 August 2019. Data was collected using an interview based questionnaire to obtain socio-demographic data, clinical characteristics, Physical activity assessed using Global Physical Activity Questionnaire (GPAQ) and standardized questionnaire developed by the Centers of Diseases Control and Prevention for determining barriers of physical activity. Data were analyzed using descriptive statistical approach.
\end{abstract}

Results: Participant were 400 patients with mean age of $57.0+9.4$ years, $64.3 \%$ of the sample were females. (72.3\%) of the sample were illiterate, $77.5 \%$ were either unemployed or housewives. $83.8 \%$ of the sample were married, $80.25 \%$ of samples had first degree relative positive family of diabetes. $56.5 \%$ of samples take oral hypoglycemic mediactons.39.2\% of samples were overweight and $83.7 \%$ of samples had poor glycemic control.57.8\% of participants didn't meet recommendations ( $<600$ minutes per week) of physical activity. The main barriers that keeps patients from being active were lack of energy (54.8\%), lack of willpower (53\%), and lack of skill (49.3\%).

Conclusions: According to the finding of the study type 2 diabetic patients had insufficient physical activity to meet the recommended level necessary to achieve optimal glycaemic control, prevent or decrease diabetic complications. Interventions should include guiding individuals to evolving recreational physical activity and overwhelming barriers to physical activity.

Keywords: Physical activity, Type 2 Diabetes Mellitus, glycemic control, overweight, lack of energy

Published: $30 / 11 / 2020$

\section{INTRODUCTION}

Diabetes is a serious, long-standing disease that develops either when the pancreas does not make adequate insulin (a hormone that regulates blood glucose), or when the body cannot definitely use the insulin it produces. Diabetes has turn into one of the major causes of morbidity and mortality across the globe. It is combined with large varieties of complications like retinopathy, neuropathy and lower limb amputation [1].The rising prevalence of diabetes mellitus conceives medical and social leads to the diabetic complications. If comorbid diseases of diabetes which are hyperlipidemia, hypertension and obesity accordingly labeled, restriction of these complications is achievable. Physical activity, dietary adjustment and counseling 
therapy are part of the overall treatment strategy in type 2 diabetic patients [2].World Health Organization (WHO) defines physical activity as any movement of the body that composed by skeletal muscles that requires energy consumptionincluding activities attempted while working, playing, carrying, travelling, and inviting in recreational pursuits. Inadequate physical activity is one of prominent risk factors for global mortality and people who are insufficiently active have a $20 \%$ to $30 \%$ increased risk of death compared to whom are sufficiently active [3]. Regular exercise can offer both general health benefits and diabetes-specific health benefits. It can reduce the cardiovascular risk by improving lipid profile, lowering the blood pressure and inducing weight loss [4]. Appraisal and Highlighting barriers are very necessary to develop and apply effective physical activity programs and guidelines to diabetic patients according to the barriers. Western community has reported lack of time [5] [6], lack of knowledge, lack of willpower [7]. in Arab countries data on barriers to physical activity in both public and type 2 diabetic patients are lack of time [8] and lack of resources [9]. No study in Iraq even in Kurdistan region on physical activity among type 2 diabetic patients, the aim of this study was to assess physical activities and determine barriers to physical activity among type 2 diabetic patients.

\section{METHODS}

A descriptive cross-sectional interviewbased study was conducted among 400 type 2 diabetic patients in Layla Qasim Health Center for Diabetes in Erbil City during May 27 to August 30, 2019. The sample size was determined by Epi. Info software (Version 7) used for sample size estimation. The expected frequency (25\%) based on the study done in United Arab Emirates [10] and confidence interval of $95 \%$.
The population size 2433 number of diabetic patients that visited Layla Qasm center from April 2018 to April 2019 accordingly the estimated sample size by Epi. Info was 380 but the researcher decided to select 400 cases as a sample size to be more accurate representative sample. Researcher attained confirmation of the Ethics Committee at the College of Nursing at 13, June 2019 (number 68), Hawler Medical University and the official approval from the Ministry of Health in Erbil Directorate of Health was taken. A questionnaire prepared for collecting data based on Global Physical Activity Questionnaire [11] and The Centers of Diseases Control and Prevention questionnaire [12] for determining barriers of physical activity were used. The questionnaires are reliable and accessible in public, no arrangements are actually needed to practice it, and it its open entry and broadly tested for reliability and validity in nine [13] countries also in Ireland [14], USA [15] and Bangladesh [16].Pilot study was conducted on 20 included type 2 diabetic patients were selected purposively from Layla Qasim Health Care Center on April 2019 and re-tested after 15 days' same patients were asked same questions. The pilot study was useful to determine the reliability, clarity, acceptability and time estimation for each participant to complete the interview which was 30-40 minutes. The results of two analyzing (test and re-test) were checked to determine the reliability by calculating Cronbach's Coefficient Correlation it was 0.87 .Sociodemographic data of diabetic patients Included age, gender, marital status, educational level, occupation and family income, and medical data of samples included family history, duration of diabetes, types of treatment, body mass index and glycemic control. Physical Activity Assessment

Physical activity level of patients with type 2 diabetes mellitus T2DM were 
determined by using Global Physical Activity Questionnaire (GPAQ). It is comprised of 16 questions about physical activity in a typical week and determines physical activity in three domains, work, transportation and recreational activities. The ratio of a person's functioning metabolic rate relative to the resting metabolic rate is called metabolic equivalent (MET). In the estimation of a person's overall energy consumption, 4 METs was given to the time used in moderate activities, and 8 METs to the time used in vigorous activities. The total time used on physical activity during a typical week, the number of days as well as the intensity of physical activity is taken into account to calculate for the categorical indicator, through a week, including activity work, during transport and leisure time, adults should do at least 150 minutes of moderate- intensity physical activity, 75 minutes of vigorous-intensity physical activity and an equivalent combination of moderate-and vigorous - intensity physical activity achieving at least 600 METminutes. Total physical activity METminutes/week (=the sum of the total MET minutes of activity computed for each setting) Equation: physical activity METminutes/week $=\left[(\mathrm{P} 2 * \mathrm{P} 3 * 8)+\left(\mathrm{P} 5^{*} \mathrm{P} 6 * 4\right)+\right.$ $\left.(\mathrm{P} 8 * \mathrm{P} 9 * 4)+\left(\mathrm{P} 11^{*} \mathrm{P} 12 * 8\right)+(\mathrm{P} 14 * \mathrm{P} 15 * 4)\right]$

The two levels of physical activity suggested for classifying patients, not meeting recommendations (MET<600 minutes per week) and Meeting recommendations (MET $\geq 600$ minutes per week). Center for Disease Control (CDC) questionnaire barriers to Physical Activity Center for Disease Control questionnaire 'Barriers to Being Active' was used in a study which is 21 questions on seven barriers (lack of time, lack of social support, lack of energy, lack of willpower, fear of injury, lack of skill and lack of resources). A set of three related questions (total of 21 questions) given in random order within the questionnaire one barrier category. A scoring system was used to demonstrate how likely each statement/item was considered to be a barrier (very likely $=3$, somewhat likely $=2$, somewhat unlikely $=1$, very unlikely $=0$ ). Scores of the three theme-related questions were added up to provide a total for each category of barriers. A score of $\geq 5$ was considered as an important barrier to overcome.

\section{RESULTS}

Table 1 shows the socio-demographic characteristics of the study sample, the mean age + SD was $57.0+9.4$ years and the highest percentage of the patients $38.8 \%$ were within the age groups $55-64$ years. Regarding to the gender, more than half of the sample $64.3 \%$ were female and the minority were male $35.8 \%$. Furthermore, $83.8 \%$ of the sample were married, most of them were illiterate $72.8 \%$, and $77.5 \%$ were either unemployed or housewives and regarding the income was enough for $44.5 \%$ of the patients and only $13.8 \%$ were exceeded needs. Table 2 shows the medical data of samples $72.75 \%$ had positive family of diabetes. In relation to the duration of diabetes mellitus by years, the highest percentage $56 \%$ of the sample in durations of diabetes mellitus was 1-8 years, while the lowest percentage $0.8 \%$ was $\geq 25$, with the mean duration of 8.61 years. the majority of the patients take oral hypoglycemic drugs, either alone $56.5 \%$, in combination with insulin $15.8 \%$, or in combination with a dietary regimen 9.8\%. about BMI 39.2\% were overweight and majority of patients had poor glycemic control based on Hba1c $\geq 783.8 \%$. Results shows that more than half $57.8 \%$ of the sample didn't meet the recommended score for physical activity (Table 2). Results also shows (Table 3 ) that the main barriers that keeps patients from being active were lack of energy $54.75 \%$, lack of willpower $53 \%$, and lack of skill $49.25 \%$. 
Table 1: Socio-demographic characteristics of study sample

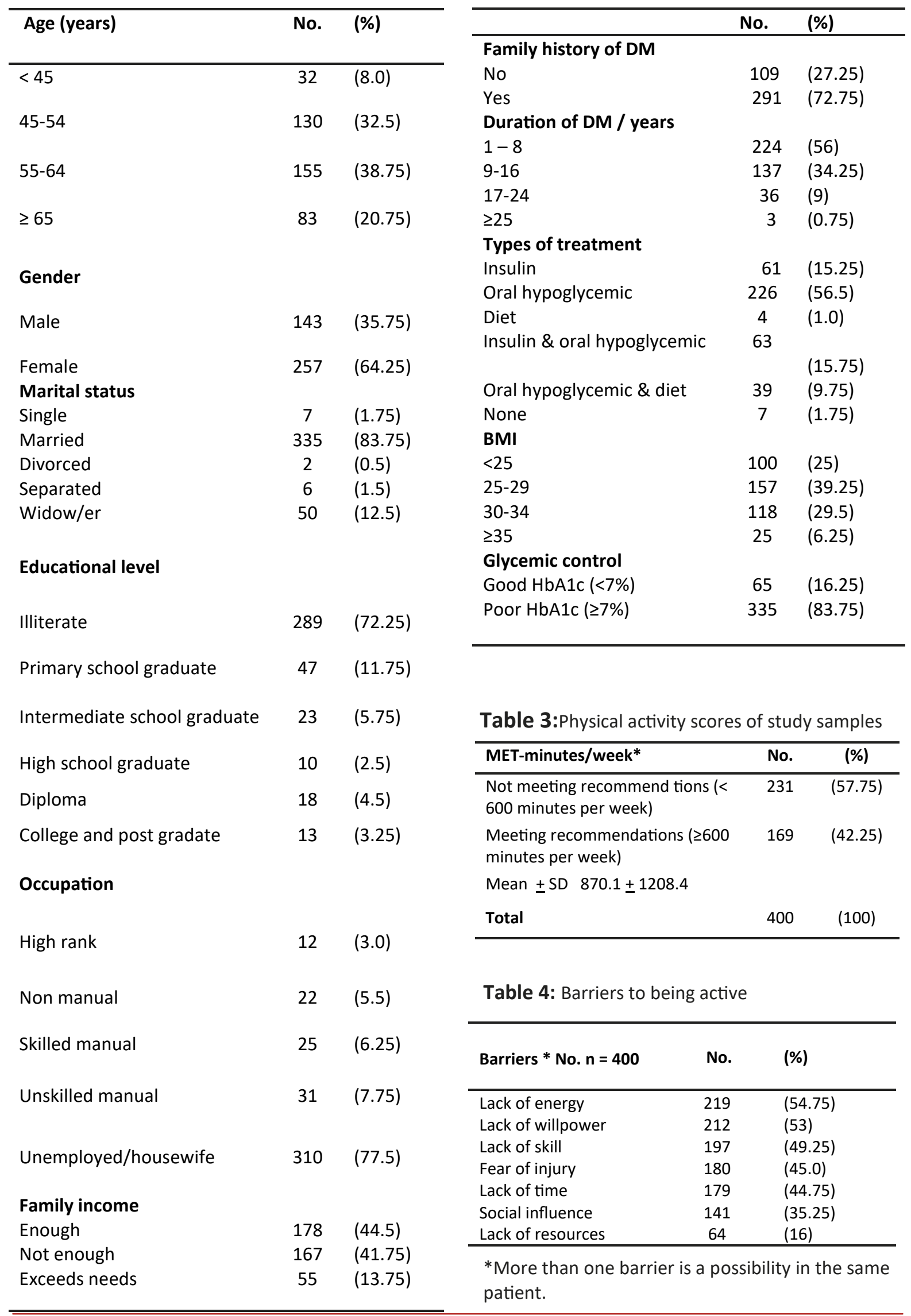

Table 2: Medical data of study participants 


\section{DISCUSSION}

The mean age of current study is $56.9 \pm 9.3$ which agree with the result of previous study done on 320 type 2 diabetic patients who found that most of participants were between 45 -65-year-oldandthe mean age was 55 years old [17]. Most of the patients in this study were female and married which is persistent with earlier studies that demonstrated similar results [17] [18]. Majority of patients in this study were housewives as supported by study done in Iran [19]. The present study findings show that the highest percentage $(80.25 \%)$ of patients had positive family history of diabetes for a first degree relative similar to study results done in Saudi Arabia [20]. About the duration of diabetes higher percentage was between 1-8 years with the mean and standard deviation $8.61 \pm 5.4$. This result agrees with the study done in Emirates [10]. in addition, majority of them were taking oral hypoglycemic medications, this concurs with a cross-sectional survey conducted on 305 type 2 diabetic patents in Oman [21]. Results show that high proportion of the study samples has poor glycemic control $(\geq 7 \%)$ with the mean and standard deviation of $8.7 \pm 1.6$ finding come along with a cross-sectional study done in Philippine which reported that the higher proportion (89.4\%) pf patients had Poor glycemic control ( $\geq 7 \%$ ) [22]. The present study finding show poor glycemic control was associated with low or insufficient physical activity practices, being active physically aids in glycemic control by increasing insulin sensitivity thus maintaining good glycemic control. The majority of patients had inadequate physical activities in Erbil city and more than half of patients didn't meet recommended guidelines of physical activity, this finding is similar to a study done among type 2 diabetic patients in Emirates [10], Pakistan [23] and UK
[24].Insufficient physical activity could be related to many factors, in our study we found that high level of illiteracy, older age are main factors perhaps due to the matter that individuals aged older tend to prefer less intense activity. The level of physical activity has definitely declined in recent years due to changing in lifestyle and enhancing in wellbeing facilities. Living in urban areas, applying elevators approximately in all buildings and the improvement of public transportation systems, expanding markets and shopping centers promote to a reduction in physical activity level. Three barriers were derived through the determination of barriers to physical activity practice in patients with type 2 diabetes in this study. Lack of energy towards physical activity was the main barrier. Studies shown that type 2 diabetic patients often struggle with lack of energy and fatigue, which affects their self-care and quality of life, also fatigue has been related to physical inactivity, depression, high body mass index, sleep disturbance, and chronic lo-grade inflammation [25]. Findings revealed that lack of willpower has been reported as second important barrier to physical activity practice in patients with diabetes. A previous study also indicated lack of willpower as the most influencing factor for low physical activity level among type 2 diabetes mellitus patients [21] [26].

\section{CONCLUSION}

The study stated that the majority of the type 2 diabetic patients in Erbil didn't meet recommended guidelines of physical activities mostly patients with poor glycemic control and older age. study also identified lack energy and lack of willpower as the most common barriers to achieving physical activities. We should provide arrangements toward establishing the programs on how to strengthen our patients 
to have continued exercise that improve health and applying strategies to overwhelming these barriers and developing motivators are crucially needed.

\section{RECOMMANDATIONS}

- $\quad$ Health care providers have crucial role in explaining the effects of physical exercise on blood glucose control, health benefits of physical activity, and eventually on the quality of life also they play role in patients monitoring, weight reduction, counseling and appropriate management of diabetes.

- Regular physical activity should be improved among diabetic patients to achieve optimal glycaemic control and prevent complications of diabetes.

- Approaches that strengthen will power and strategies to enhancing energy include (maintaining healthy weight, eating healthy diet, regular exercise, adequate rest and sleep, stress restriction and meditation.

\section{CONFLICT OF INTREST}

The author reports no conflict of interests.

\section{REFRENCES}

[1] Atlas, Diabetes. "International diabetes federation." IDF Diabetes Atlas, 7th edn. Brussels, Belgium: International Diabetes Federation. 2015. Available from: https:// suckhoenoitiet.vn/download/Atla-benh-daithao-duong-2-1511669800.pdf [Accessed 18th Dec 2019 .

[2] Laaksonen DE, Lindström J, Lakka TA, Eriksson JG, Niskanen L, Wikström K, et al. Prevention of type 2 diabetes mellitus by changes in lifestyle among subjects with impaired glucose tolerance. New England Journal of Medicine, 2005.Jan;54(1):15865.2005.Availablefrom:https:www.ncbi.nlm. nih.gov/pubmed/15616024[Accessed 10thSep 2019 .
[3] World Health Organization. WHO Physical Activity. (2018). Available from: http:// www.who.int/dietphysicalactivity/pa/en/ [Accessed 9th Nov 2019.

[4] The Look AHEAD Research Group. Longterm effects of a lifestyle intervention on weight and cardiovascular risk factors in individuals with type 2 diabetes mellitus. Archives of internal medicine. 2010;170 (17):1566. Available from: https:// www.ncbi.nlm.nih.govepubmed/2087640 8 [Accessed 10th Sep 2019.

[5] Egan AM, Mahmood WA, Fenton R, Redziniak N, KyawTun T, Sreenan S,et al. Barriers to exercise in obese patients with type 2 diabetes. The Quarterly journal of medicine. 2013;10(6):635-8. Available from: https://www.ncbi.nlm.nih.gov/ pubmed/23525164 [Accessed 20th Sep 2019.

[6] Korkiakangas EE, Alahuhta MA, Laitinen $\mathrm{JH}$. Barriers to regular exercise among adults at high risk or diagnosed with type 2 diabetes: a systematic review. Health Promotion International.2009;2(4):41627.Availablefrom:https://

www.semanticscholar.org/paper/Barriers -to-regular-exercise-among-adults-athigh2KoriakangasAlhuhta/0df7115de8308 36731277012eae963e499ac8b02

[Accessed 20th Sep 2019]

[7] Booth, A.O., Lowis, C., Dean, M., Hunter, S.J. and McKinley, M.C. Diet and Physical Activity in the Self-Management of Type 2 Diabetes: Barriers and Facilitators Identified by Patients and Health Professionals. Primary Health Care Research \& Development.(2013) 14, (2)93-306.Available from: https:www.ncbi.nlm.nih.govepubmed/23 739524 [Accessed 13th Oct 2019 ]

[8] Serour M, Alqhenaei H, Al-Saqabi S, Mustafa AR, Ben-Nakhi A. Cultural factors and patients' adherence to lifestyle measures. British Journal of General Practice. 2007. 57(537):291-295.Available from: https:// www.ncbi.nlm.nih.govepubmed/1739473 2 [Accessed 10th Oct 2019]

[9] AlQuaiz AM, Tayel SA. Barriers to a healthy lifestyle among patients attending primary care clinics at a university hospital in Riyadh. Annals of Saudi Medicine. 2009;29:30-5.Available from: https:// www.ncbi.nlm.nih.gov/ pubmed/19139617 [Accessed 13th Oct 2019 ] 
[10] Al-Kaabi J, Al-Maskari F, Saadi H, Afandi B, Parkar H, Nagelkerke N. Physical Activity and Reported Barriers to Activity Among Type 2 Diabetic Patients in the United Arab Emirates. The Review of Diabetics Studies. 2009;6(4):271. Available from: https:// www.ncbi.nlm.nih.gov/pmc/articles/ PMC2836198 / [Accessed 10th Sep 2019]

[11] World Health Organization. Global physical activity surveillance. In: Chronic diseases and health promotion; 2016. http:// www.who.int/chp/steps/GPAQ/en/ [Accessed 20th August2019]

[12] CDC. "Overcoming barriers to physical activity": Centers for disease control and prevention, 2011. Available from: https:// www.ucd.ie/issda/t4media/

BarriersToBeingActiveQuestionnaire_Section7_Q4.pdf [Accessed 19th Dec 2019 ]

[13] Bull FC, Maslin TS, Armstrong T: Global physical activity questionnaire (GPAQ) nine country reliability and validity study. Journal of Physical Activity Health. 2009, 6:790-804. Available from: https:// pdfs.semanticscholar.org/45fd/9a5df90a3b a5580428c3d3cc85e8c141a826.pdf [Accessed 20th Oct 2019]

[14] Cleland CL, Hunter RF, Kee F, Cupples ME, Sallis JF, Tully MA. Validity of the global physical activity questionnaire (GPAQ) in assessing levels and change in moderatevigorous physical activity and sedentary behavior. BMC Public Health. 2014;14:1255 -65. Available from: https:// bmcpublichealth.biomedcentral.com/ articles/10.1186/1471-2458-14-1255 [Accessed 17th Oct 2019]

[15] Herrmann SD, Heumann KJ, Der Ananian CA, Ainsworth BE. Validity and reliability of the global physical activity questionnaire (GPAQ). Measurement in Physical Education and Exercise Science. 2013;17:221-35. Available from: https:// www.tandfonline.com/doi/ abs/10.1080/1091367X.2013.805139 [Accessed 20th Sep 2019]

[16] Shirin JM, LiaquatA, Anthony B and Dafna M. Validity of the global physical activity questionnaire (GPAQ) in Bangladesh. BMC Public Health (2017) 17:650. Available from: https://www.ncbi.nlm.nih.gov/pmc/ articles/PMC5553893/ [Accessed 15th Oct 2019 ]
[17] Fattahi A, Barati M, Bashirian S, Moghadam $\mathrm{RH}$. Physical Activity and Its Related Factors Among Type 2 Diabetic Patients in Hamadan. Iranian Journal Of Diabetes and Obesity. 2014; 6(2), 85-92. ijdo.ssu.ac.ir

[18] Shazwani N, Suzana S, Hanis Mastura Y, Lim CJ, Teh SC, Mohd Fauzee MZ, et al Assessment of Physical Activity Level among Individuals with Type 2 Diabetes Mellitus at Cheras Health Clinic, Kuala Lumpur. MaIaysian Journal of Nutrition. 2010; 16(1): 101 - 112. ncbi.nlm.nih.gov

[19] Naderimagham, S., Niknami, S., Abolhassani, F. Development and psychometric properties of a new social support scale for self-care in middle-aged patients with type II diabetes (S4-MAD). BMC Public Health. 2012; 12(1), 103. Available from: https:// bmcpublichealth.biomedcentral.com/ articles/10.1186/1471-2458-12-1035 [Accessed 20th Oct 2019]

[20] Mohamed BA, Almajwal AM , Saeed AA and Bani IB. Dietary practices among patients with type 2 diabetes in Riyadh, Saudi Arabia. Journal of Food, Agriculture \& Environment.2013;11(2):110-114. Available from: https:// www.academia.edu/34494751/

Dtary_practices_among_patients_with_typ e_2_Diabetes_in_Riyadh_Saudi_Arabia [Accessed 18th Dec 2019 ].

[21] Alghafri T, Alharthi SM, Al Farsi YM. Perceived barriers to leisure time physical activity in adults with type 2 diabetes attending primary healthcare in Oman: a cross-sectional survey. BMJ Open 2017;7:e016946.

[22] Palermo M, Majorie; Sandoval MA. Assessment of Physical Activity Level among Patients with Type 2 Diabetes Mellitus at the UP - Philippine General Hospital Diabetes Clinic. Journal of the ASEAN Federation of Endocrine Societies.2016; 31(2),144. Available at: https:// asean-endocrinejournal.org/index.php/ JAFES/article/view/336 [Accessed 28th Oct2019 ].

[23] Arshad R, Younis BB, Masood J, Tahira M, Khurhsid S. Pattern of physical activity among persons with Type-2 diabetes with special consideration to daily routine. Pakistan Journal Medical Sciences. 2016;32 (1):234-238. 
[24] Thomas N, Alder E, Leese GP. Barriers to physical activity in patients with diabetes. Postgraduate Medical Journal. 2004 May;80(943):287-91. Available from: https://www.ncbi.nlm.nih.gov/pmc/ articles/PMC1742997/ [Accessed 11th Oct 2019 ]

[25] Fritschi C, Fink MA. fatigue in adults with type 2 diabetes-an overview of current understanding and management approages.US Endocrinology. 2012;8(2):8487. Available from: https:// www.touchendocrinology.com/fatigue-inadults-with-type-2-diabetes-an-overviewof-current-understanding-andmanagement-approaches-2/ [Accessed 12th Oct 2019 ]

[26] Ghimires . Barriers to Diet and Exercise among Nepalese Type 2 Diabetic Patients. Hindawi International Scholarly Research Notices Volume 2017;2017 Available from: https://www.researchgate.net/ publication/321062658_Barriers_to_Diet_and_Ex ercise_among_Nepalese_Type_2_Diabetic _Patients [Accessed 20th Oct 2019] 